\title{
Body-packing: a case of hundred condoms of illicit drug swallowed by a trafficker
}

\begin{abstract}
A 55 year old man on transit in Bole international airport was brought to a hospital with sign and symptoms of intestinal obstruction. A complete intestinal obstruction was suspected and laparotomy was done. Milking down the obstructing foreign bodies tried but failed and the foreign bodies were extracted through an enterotomy. One hundred condoms filled with illicit drugs were extracted successfully. This is the first report of body packing in scientific literature in Ethiopia. We report the case and discuss the phenomenon with literature review.
\end{abstract}

Keywords: body packing, foreign bodies, drug trafficking, cocaine, illicit
Volume 6 Issue 5 - 2017

\author{
Hailu Wondimu Gebresellassie \\ Department of surgery, Addis Ababa University, Ethiopia
}

Correspondence: Hailu Wondimu Gebresellassie, Department of surgery, school of medicine, college of health sciences, AAU, Addis Ababa, Ethiopia, Tel+251911630934,

Email hailuwgs@gmail.com

Received: April 24, 2017 | Published: May 02, 2017

\section{Introduction}

Foreign bodies in the digestive and respiratory system are a common cause of morbidity and mortality. Ingestion of foreign bodies is in many cases are accidental. Foreign bodies present with pain, wound, infection and discharging sinus. ${ }^{1,2}$

Drug traffickers ingest drugs to evade detection occurs in two distinct patterns. "Body packing" is the planned and relatively wellcoordinated ingestion for the purposes of smuggling. ${ }^{3}$

"Body stuffing," the hasty ingestion of drugs in order to evade law enforcement, is a distinct syndrome from body packing.. The body stuffer is often at risk for acute toxicity because the drugs are usually unwrapped or poorly wrapped, and not designed for ingestion and transport. $^{3}$

\section{Case presentation}

A 55year old Nigerian man was brought to a hospital from Bole international airport for a complaint of severe crampy abdominal pain of four hours duration. There were associated two episodes of bilious vomiting. He claims to have swallowed 100 condom-like materials filled with illicit drugs.

On examination he was sick looking but in no form of cardiorespiratory distress. Vital signs were normal except mild hypertension. The pertinent findings were moderately distended abdomen with hyperactive bowl sounds. The rectum was empty on digital examination.

Investigation with plain film of abdomen revealed classical evidences of body packing. Laparotomy revealed multiple discrete masses of similar shape and size in the intestine from jejunum down to sigmoid colon. An attempt to push all down to the rectum was tried but aborted after removing some twenty of the materials by milking down to anus and an enteretomy was done in the ileum and all the rest were removed intact. The enterotomy opening was closed and peritoneal cavity lavaged with saline and abdomen closed. Postoperatively on $5^{\text {th }}$ postop day patient was transferred to another facility by law enforcement officials.

\section{Discussion}

Esophagus is the site where foreign bodies are often found especially in children. ${ }^{1}$ Most go down to stomach and in to intestine without complication. The most common site of lodgment is the distal small bowl, i.e., ileo-cecal region in one-third of the cases. Those patients often present with abdominal pain due to lodgment or peritonitis within days as in our patient. ${ }^{2}$

Ingestion is not the only way of introducing foreign bodies. Foreign bodies can be introduced in to the anus accidentally or intentionally for erotic purposes, for self-treatment, for concealment, or by assault as well. ${ }^{4}$

Body-packing is a known means of international drug smuggling. This method was first reported in the medical literature in 1973, describing a patient who had swallowed a condom filled with hashish. ${ }^{5}$ It is mainly used for heroin, cocaine, amphetamines, and cannabis carriage. Latex condoms are commonly used for this purpose as this are readily available ${ }^{6}$ (Figure 1 ) (Figure 2).

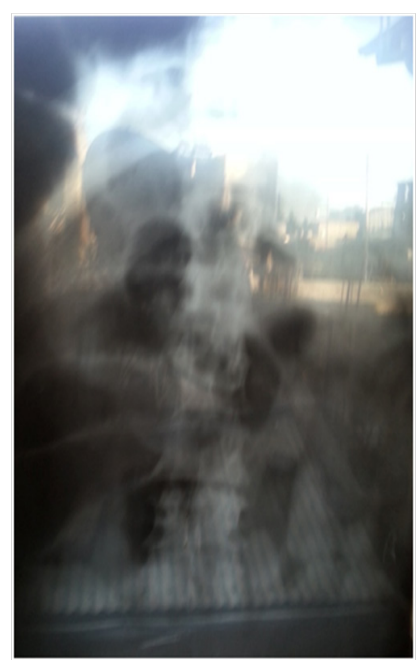

Figure I Condom bags filled with ilicit drugs in plain film of abdomen. 


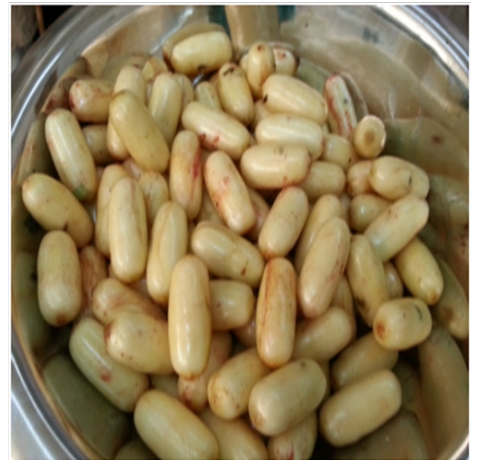

Figure 2 Condoms filled with drugs after removal.

Traffickers use constipating agents, such as diphenoxylate or loperamide, for keeping the packets in gastrointestinal tract until they reach their destination. After entering the country of destination, body packers use laxatives, cathartics, or enemas to help pass their cargo rectally. ${ }^{7}$

Although persons carrying more than 200packets have been described. ${ }^{3}$ One packet of cocaine, heroin, or amphetamine contains a potentially life-threatening dose of drug. ${ }^{6}$ Body packers may present to the emergency department because of drug toxicity, intestinal obstruction, or more commonly, requested by law-enforcement officers for medical confirmation or exclusion of suspected body packing. ${ }^{6}$

History is important although traffickers are unlikely to tell the truth. A plain abdominal radiograph is the initial method of choice for the detection or exclusion of drug-filled packets within the gastrointestinal tract of body packers. The findings are multiple radio dense foreign bodies with unnatural uniformity, as in this case, a rosette-like finding formed by air trapped in the knot where a condom is tied, or a double-condom $\|$ sign, in which air trapped between layers of latex making them more visible. ${ }^{8}$ Air around the latex may also suggest a loss of integrity of the packing material. Plain abdominal radiography has a sensitivity of $74 \%-100 \%{ }^{9}{ }^{9}$

Ultrasound is safe and can be done on bedside and urgently hence can be used for initial evaluation. Contrast-enhanced CT easily identifies drug packets, which typically appear as foreign bodies surrounded by a small amount of gas. CT is more sensitive than plain radiography, but sufficient assessment of sensitivity is lacking. ${ }^{10}$

Currently accepted management of asymptomatic patients is to wait for it to pass and this happens usually in 3 to 6days. The overall rate of failure, defined as any indication for surgery, of such conservative management, is only about 5 percent. ${ }^{6}$ Surgery may be indicated for patients with acute cocaine poisoning or gastrointestinal obstruction or perforation. Open surgery is safer than endoscopy because of risk of rupture with the latter. ${ }^{6}$

\section{Conclusion}

Addis Ababa being in strategic location in the horn of Africa and the rise of the problem of drug trafficking, ${ }^{11}$ doctors should be aware of the problem of body packing and its clinical management.

\section{Acknowledgements}

I would like to thank the staffs Hayat hospital for their support during evaluation and management of these patients.

\section{Consent}

A proper consent was obtained from the patient.

\section{Conflict of interest}

The author declares no conflict of interest.

\section{References}

1. Ambe P, Weber SA, Schauer M, et al. Swallowed foreign bodies in adults. Dtsch Arztebl Int. 2012;109(50):869-875.

2. Palta R, Sahota A, Bemarki A, et al. Foreign body ingestion :characteristics and outcomes in a lower socioeconomic population with predominantly intentional ingestion. Gastrointest Endosc. 2016;69(3 Pt 1):426-433.

3. Booker RJ, Smith JE, Rodger MP. Packers, pushers and stuffers - managing patients with concealed drugs in UK emergency departments :a clinical and medicolegal review. Emerg Med J. 2009;26(5):316-320.

4. Anderson KL, Dean AJ. Foreign bodies in the gastro intestinal tract and a no rectal emergencies. Emerg Med Clin NA. 2011;29(2):369-400.

5. Internal concealment of drugs of abuse (body packing). Internet; 2012.

6. Jesus M, Perez S, Luis J, et al. Hashish body packing : a case report. Case Reports in Medicine. 2009;712573:3.

7. Emergent surgery for body packing what happens to the drugs ? PubMed Commons. 2015;75(4):1-2.

8. Ramrakha PS. Drug smuggler's delirium Measuring outcome of perinatal. 1993;306(April).

9. Ciszowski K, Hydzik P, Waldman W, et al. Cocaine smuggling in the gastrointestinal tract - the case report with the review of literature. Przegl Lek. 2015;62(6):492-498.

10. Creel SA, Girish G, Jamadar DA, et al. Sonographic surface localization of subcutaneous foreign bodies and masses. $J$ Clin Ultrasound. 2009;37(3):158-160.

11. Ellis S. West Africa' S International drug trade. African Affairs. 2009;108(431):171-196. 